\title{
Repercussões da nova gestão pública na gestão da educação: um estudo da rede estadual de Goiás ${ }^{1}$
}

\section{Repercussions of the new public management in education management: a study of Goiás state education network}

\author{
Luciana Rosa Marques*
}

\begin{abstract}
RESUMO
O modelo da Nova Gestão Pública (NGP) tem se tornado hegemônico no Brasil. Calcado em metas, resultados e em avaliações de larga escala, tem sido adotado por vários estados no país. Seus preceitos têm sido implantados também na educação. Este estudo busca verificar quais as repercussões da NGP na gestão da educação na rede pública estadual de Goiás, estado que vem se destacando pelos bons resultados alcançados em avaliações de larga escala. Tomando por base os construtos da Teoria do Discurso, proposta por Ernesto Laclau e seus seguidores, a pesquisa foi realizada a partir de entrevistas com os dirigentes das escolas de maior e menor do Índice de Desenvolvimento da Educação Básica (IDEB) do estado, do sindicato dos profissionais de educação e da secretaria de educação, além da análise das diretrizes governamentais. Verificamos que a NGP é hegemônica na política educacional do estado, constituindo-se como um ponto nodal. No entanto, a gestão democrática também é fulcral no discurso dos entrevistados, podendo ser considerada também como um ponto nodal.
\end{abstract}

Palavras-chave: Nova Gestão Pública. Gestão Educacional. Política Educacional. Teoria do Discurso.

1 Apoio Conselho Nacional de Desenvolvimento Científico e Tecnológico (CNPQ).

*Universidade Federal de Pernambuco. Recife, Pernambuco, Brasil. E-mail: Imarques66@ gmail.com. https://orcid.org/0000-0001-6002-5953. 


\begin{abstract}
The New Public Management (NGP) has become hegemonic in Brazil. Based on goals, results and large scale assessments, it has been adopted by several states in the country. Its precepts have also been implanted in education. This study seeks to verify the repercussions of NGP in education management in the state public education network of Goiás, a state that has been highlighted by the good results achieved in large scale evaluations. Based on the constructs of Discourse Theory, proposed by Ernesto Laclau and his followers, the research was conducted from interviews with the leaders of the state's largest and smallest IDEB schools, the union of education professionals and the education secretariat, in addition to analysis of government guidelines. We verify that the New Public Management is hegemonic in the educational policy of the State, constituting itself as a nodal point. However, democratic management is also central to the interviewees' discourse, and it is also a nodal point.
\end{abstract}

Keywords: New Public Management. Educational management. Educational policy. Discourse Theory.

\title{
Introdução
}

Temos observado, nos últimos tempos, a emergência de novos modelos de regulação estatal, dentro do espectro do que vem se denominando por Nova Gestão Pública, que pode ser considerada um movimento de reforma do Estado, cujo objetivo era responder à crise econômica dos anos 1970, dentro do marco da regulação capitalista.

De forma geral, a Nova Gestão Pública pode ser definida como um programa de reforma do setor público com base em instrumentos da gestão empresarial que visa melhorar a eficiência e eficácia dos serviços públicos nas burocracias modernas, sendo uma resposta às duas grandes forças que definiram as últimas décadas do século XX: a globalização e a democracia. A NGP se constitui atualmente como o modelo hegemônico da administração pública ocidental.

Segundo Bresser Pereira (2000), o sistema capitalista teve duas grandes reformas na administração pública: a reforma burocrática e a reforma gerencial (ou reforma da nova gestão pública), que podem ser divididas em duas "ondas". A primeira, nos anos 1980, com ênfase no ajuste estrutural da economia em crise, e a segunda, a partir dos anos 1990, que enfatiza as transformações institucionais. 
Junquilho (2002, p. 2) aponta as seguintes características básicas da NGP que, segundo ele, podem ser encontradas, inclusive, em países que não tiveram completamente desmontadas as políticas típicas do Estado de Bem Estar Social:

- A ideia do gasto público como custo improdutivo ao contrário de investimento coletivo e social;

- A identificação dos servidores públicos como hostis à sociedade, detentores de privilégios e defensores de interesses particulares;

- A crítica à interferência negativa do Estado nos mercados e a eleição da supremacia destes últimos como mecanismos mais apropriados de distribuição de bens e serviços à sociedade;

- A definição do Estado com o papel principal de promotor/empreendedor, ao invés de provedor de bens e serviços sociais;

- A importação de práticas gerenciais comuns ao setor privado da economia, incluindo nas agendas públicas temas como: eficiência, eficácia, produtividade, avaliação e controle de resultados, satisfação do consumidor, delegação e gestão participativa, prevenção e controle de gastos; - A ênfase na importância do poder e na mudança de papel dos chamados administradores públicos para gerentes ou gestores públicos profissionalizados, no sentido de que passa a ser desejado um perfil voltado à noção de orientador/integrador e empreendedor, distinto do papel de supervisor ou administrador;

- A privatização de setores econômicos produtivos estatais;

- A ênfase na desregulação dos mercados comerciais e de trabalho.

De acordo com Dasso Júnior (2014, p. 14), “é demasiado simplista definir a 'Nova Gestão Pública' como um modelo único de 'teoria de administração pública'. As diversas variantes surgidas em diferentes países, com histórias e culturas absolutamente distintas fazem com que as práticas sejam distintas". Para o Conselho Latino-Americano para o Desenvolvimento (CLAD), a implantação da NGP na região deve atender às seguintes particularidades:

- Profissionalização da alta burocracia;

- Transparência e responsabilização;

- Descentralização na execução de serviços públicos;

- Desconcentração organizacional nas atividades exclusivas do Estado;

- Controle dos resultados;

- Novas formas de controle;

- Duas formas de unidades administrativas autônomas: agências que 
realizam atividades exclusivas do Estado e agências descentralizadas, que atuam nos serviços sociais e científicos;

- Orientação da prestação de serviços para o cidadão usuário;

- Modificação o papel da burocracia com relação à democratização do poder público (CLAD, 1998).

Cabe destacar que movimento da NGP não se consolida no sentido de desmantelamento do Estado, mas de sua reconstrução. O documento do CLAD reforça "a relevância da reforma gerencial para a reconstrução da capacidade dos estados e a identificação dos limites das orientações neoliberais como resposta à crise do Estado de Bem Estar Social" (GARCIA; ADRIÃO; BORGHI, 2009, p. 12), em oposição à resposta neoliberal de redução do Estado e predomínio total do mercado, tratando-se de uma mudança estrutural no funcionamento do Estado.

Para reconstruir la gestión pública el Estado debe redefinir sus funciones y su forma de actuación además de incrementar la capacidade de gestion estatal (governance) mediante la profesionalización de la burocracia estratégica, el fortalecimento de sus instrumentos gerenciales y el ejoramiento de su desempeño en la elaboración de políticas. Sin embargo, la realización de modificaciones em el aparato administrativo no es suficiente. Es imprescindible la recuparación de las bases de legitimidade y de la eficácia social de la acción governamental, es decir, de la governabilidade de los países (CLAD, 1998, p. 1).

A NGP segue a lógica do privado, que deve ser referência para o setor público, tornando o modelo empresarial universalmente válido para pensar a ação pública e social. Suas bases epistemológicas estão no Novo Institucionalismo, enquanto suas bases políticas se encontram "na crítica ao Estado do Bem Estar Social, ao planejamento centralizado e ao papel indutor e promotor do bem estar social exercido preponderantemente pelo Estado" (OLIVEIRA, 2017, p. 710). Promovendo ataques às hierarquias, à centralização do poder e das decisões e à rigidez das estruturas governamentais, a NGP se instala como uma grande inovação, mesmo onde o Estado do Bem Estar Social não chegou a ser vivenciado.

No entanto, "inspirar-se na gestão privada é um erro conceitual grave porque a gestão pública é, pelos fins e meios, absolutamente diferente da gestão privada" (DASSO JÚNIOR, 2014, p. 16). Enquanto a lógica do público deve ser inspirada pela solidariedade, dos interesses coletivos, do cidadão, a lógica privada é determinada pela lógica mercantil do consumo, dos interesses 
individuais, do cliente, sendo, portanto, duas lógicas antagônicas. Para Dardot e Laval (2016, p. 313):

A questão é saber o que dizer da "cultura de resultado" na justiça, na medicina, na cultura ou na educação e sobre quais valores podemos julgá-la. Na verdade, o ato de julgamento, que depende de critérios éticos e políticos, é substituído por uma medida de eficiência que se supõe ideologicamente neutra. Assim, tende-se a ocultar as finalidades próprias de cada instituição em benefício de uma norma contábil idêntica, como se cada instituição não tivesse valores constitutivos que lhe são próprios.

No Brasil, a partir dos anos 1990, as propostas da NGP começam a se consolidar no sistema estatal. Assim, "quando Fernando Henrique Cardoso assume a presidência da república e institui o Ministério de Reforma do Estado, MARE, sob o comando do economista Luiz Carlos Bresser Pereira é que será proposta a reforma 'orgânica' do aparelho de estado sob a perspectiva assumida da administração gerencial” (GARCIA; ADRIÃO; BORGHI, 2009, p. 17), tendo como principais características a redução do aparelho estatal, privatização, cortes, redução do funcionalismo, além da implantação das parcerias públicoprivado, em seus diferentes formatos.

\section{A nova gestão pública e a educação}

Embora com formatos diferenciados, a NGP vem se consolidando em vários países, como uma alternativa eficiente na busca por qualidade da educação. No Brasil não tem sido diferente do que acontece nos demais países. Várias experiências vêm sendo implantadas nas diferentes redes educacionais.

Segundo Verger (2015), nos últimos anos, a NGP vem penetrando com força a agenda educativa global, tanto em países industrializados como nos em via de desenvolvimento. Os primeiros registros da NGP na educação são da década de 1980, na reforma educacional britânica, que teve repercussões diretas na gestão das escolas. A sua disseminação em âmbito internacional se deu a partir dos anos 1990 .

Os princípios da NGP transpostos à educação se cristalizam em um amplo leque de políticas, sistematizados por Verger (2015) na tabela a seguir: 
TABELA 1 - PRINCÍPIOS DA NPG E POLÍTICA EDUCACIONAL

\begin{tabular}{|c|c|}
\hline PRINCÍPIOS NPG & POLÍTICAS EDUCACIONAIS \\
\hline Gestão profissional dos serviços públicos & $\begin{array}{l}\text { - Profissionalização e empoderamento dos } \\
\text { gestores escolares }\end{array}$ \\
\hline $\begin{array}{l}\text { Normas e medidas de desempenho mais } \\
\text { explícitas }\end{array}$ & $\begin{array}{l}\text { - Definição de indicadores de qualidade e de } \\
\text { benchmarks sobre êxito educativo } \\
\text { - Padrões curriculares comuns }\end{array}$ \\
\hline Ênfase no controle dos resultados & $\begin{array}{l}\text { - Avaliação externas dos resultados e do } \\
\text { rendimento escolar }\end{array}$ \\
\hline $\begin{array}{l}\text { Desagregar o setor público em } \\
\text { pequenas unidades de gestão }\end{array}$ & $\begin{array}{l}\text { - Autonomia escolar, school-based } \\
\text { management }\end{array}$ \\
\hline Maior competição no setor público & $\begin{array}{l}\text { - Subsídios públicos para as escolas privadas } \\
\text { - Financiamento per capita } \\
\text { - Publicação dos resultados obtidos pelas } \\
\text { escolas em testes estandardizados }\end{array}$ \\
\hline Adotar o estilo gerencial do setor privado & $\begin{array}{l}\text { - Flexibilização de contratação e dispensa } \\
\text { pela escola } \\
\text { - Estilo gerencial para direção das escolas }\end{array}$ \\
\hline Restrição no uso de recursos públicos & $\begin{array}{l}\text { - Financiamento das escolas com } \\
\text { base nos resultados } \\
\text { - Remuneração dos docentes com base em } \\
\text { critérios de mérito e produtividade }\end{array}$ \\
\hline
\end{tabular}

FONTE: Verger (2015, p. 602).

A NPG tem alterado a forma como se concebe a gestão de instituições educativas, já que princípios como autonomia escolar, prestação de contas e gestão baseada em resultados têm norteado a forma como se regula, provê e financia a educação pública. No entanto, a NGP não é um modelo de reforma educacional monolítico nem adota o mesmo formato em todos os países, sendo possível observar enfoques de gestão e desenhos de política educacional bem diferenciados. No entanto, segundo Oliveira (2015, p. 631),

[...] alguns de seus princípios podem ser observados nas reformas que ocorreram nas últimas décadas em diferentes contextos nacionais, sendo eles: a dissociação das funções de execução e controle; a fragmentação das burocracias e sua abertura às demandas e exigências dos usuários; a concorrência de atores públicos com o setor privado e a terceirização dos serviços; o reforço das responsabilidades e da autonomia dos níveis 
de execução da ação pública; a gestão por resultados e a contratação (os chamados contratos de gestão) fundadas na realização dos objetivos e da avaliação de desempenho; a normalização, via padronização, das práticas profissionais baseadas em evidências e em experimentos exemplares.

A Nova Gestão Pública tem se constituído como um novo paradigma de políticas que dota os fazedores de política de categorias e modelos de marcos interpretativos nas decisões da política educacional, visando à qualidade da educação. Algumas de suas políticas podem ser consideradas, ainda, um significante flutuante $^{2}$ (LACLAU; MOUFFE, 1985). Segundo Verger (2015), as soluções da NPG não são adotadas porque funcionam, mas porque existe uma percepção generalizada de que são políticas que poderiam solucionar os problemas mais importantes dos sistemas educativos contemporâneos. O autor destaca, ainda, que a NPG vem sendo adotada tanto por governos do campo conservador quanto do progressista ${ }^{3}$. Para Dardot e Laval (2016, p. 311),

o novo modelo de governo conquistou muitos países. Os temas e os termos da "boa governança" e das "boas práticas" tornaram-se o mantra da ação governamental [...] o Banco Mundial no Relatório sobre o desenvolvimento mundial, de 1997, propôs a substituição do termo "Estado mínimo" por "Estado melhor". [...] Essa reforma genérica do Estado segundo os princípios do setor privado apresenta-se como ideologicamente neutra: visa somente à eficiência.

Buscando sintetizar as diferentes configurações possíveis da NPG na educação, Verger nos auxilia com esta tabela, destacando que a NGP pode se traduzir em múltiplas opções de políticas e intervenções, com desenhos bastante variados, e até antagônicos, o que dificulta a possibilidade de se tirar conclusões generalizáveis do impacto da NGP na educação, especialmente em termos de justiça educativa, mercantilização de serviços públicos, profissionalização docente e democracia escolar.

2 Quando um significante desliza entre diferentes processos de significação, sendo identificado de maneiras distintas, catalisando sentidos de grupos específicos do conjunto da heterogeneidade social, mas simultaneamente não assumindo a condição de representante do todo, ele passa a ser concebido como um significante flutuante, sendo vinculado a diversos sentidos específicos.

3 Para Dardot e Laval (2016), essa reinvenção do governo se apresenta com frequência como uma invenção da política de esquerda, expressando a dominação da nova razão neoliberal. 
TABELA 2 - POSSÍVEIS CONFIGURAÇÕES DA NGP NA EDUCAÇÃO

\begin{tabular}{|c|c|}
\hline POLÍTICAS EDUCATIVAS DE NGP & POSSIVÉIS CONFIGURAÇÕES \\
\hline $\begin{array}{l}\text { Profissionalização/empoderamento dos } \\
\text { diretores escolares }\end{array}$ & $\begin{array}{l}\text { - Estilo de direção hierárquico vs liderança } \\
\text { compartilhada }\end{array}$ \\
\hline $\begin{array}{l}\text { Definição de padrões curriculares comuns e } \\
\text { indicadores de qualidade e de benchmarks } \\
\text { sobre o êxito educativo }\end{array}$ & $\begin{array}{l}\text { - Diferentes níveis de padronização e prescrição } \\
\text { dos conteúdos e metodologias de ensino } \\
\text { - Presença ou ausência da equidade como } \\
\text { uma condição da qualidade educacional }\end{array}$ \\
\hline $\begin{array}{l}\text { Avaliação externa dos resultados e do } \\
\text { rendimento escolar }\end{array}$ & $\begin{array}{l}\text { - Avaliação somativa vs formativa } \\
\text { - Presença de incentivos materiais, } \\
\text { formativos ou simbólicos vinculados aos } \\
\text { resultados das avaliações } \\
\text { - Publicação ou não publicação dos } \\
\text { resultados obtidos pelas escolas em testes } \\
\text { estandardizados }\end{array}$ \\
\hline $\begin{array}{l}\text { Autonomia escolar: } \\
\text { school-based management }\end{array}$ & $\begin{array}{l}\text { - Foco da autonomia na gestão de recursos, } \\
\text { na organização escolar e/ou em assuntos } \\
\text { pedagógicos } \\
\text { - Locus da autonomia: } \\
\text { diretor } v s \text { comunidade escolar }\end{array}$ \\
\hline $\begin{array}{l}\text { Empoderamento das famílias/clientes dos } \\
\text { serviços públicos }\end{array}$ & $\begin{array}{l}\text { - Diferentes níveis e âmbitos de participação } \\
\text { das famílias (gestão, orçamento, questões } \\
\text { educativas, serviços periféricos) } \\
\text { - Dar mais voz às famílias nas escolas (para } \\
\text { que possam transmitir suas demandas e } \\
\text { preocupações ao professorado) e fomentar } \\
\text { que optem por eleições/saída das escolas } \\
\text { (dinâmica do mercado) }\end{array}$ \\
\hline $\begin{array}{l}\text { Subsídios públicos às escolas privadas: } \\
\text { financiamento per capita ou competitivo }\end{array}$ & $\begin{array}{l}\text { - O tipo de concorrência entre as escolas } \\
\text { (resultante do financiamento per capita) } \\
\text { estará condicionada pelos níveis de } \\
\text { regulação e controle da gratuidade educativa, } \\
\text { do acesso às escolas e da eleição escolar }\end{array}$ \\
\hline $\begin{array}{l}\text { Financiamento das escolas e/ou docentes com } \\
\text { base em critérios de mérito/produtividade }\end{array}$ & $\begin{array}{l}\text { - Avaliações dos docentes a nível individual } \\
\text { ou das escolas } \\
\text { - Avaliação dos docentes baseada em seu } \\
\text { domínio do currículo, nos resultados dos } \\
\text { estudantes ou nos processos de ensino }\end{array}$ \\
\hline
\end{tabular}

FONTE: Verger (2015, p. 617). 
No Brasil, as reformas com orientação da NGP começam a ser implantadas na década de 1990, tendo como argumento central a busca da eficiência dos serviços públicos. Assim, em 1995, o Ministério da Reforma do Estado publica o Plano Diretor da Reforma do Aparelho do Estado que demonstrava a intenção de tornar o Estado brasileiro mais regulador e administrador do que provedor de serviços e bens. No entanto, esse foi um período de grande efervescência política, em função do término da ditadura militar. Contraditoriamente, essas reformas eram justificadas como resultado das exigências dos movimentos sociais que lutavam pela ampliação do direito à educação pública e criticavam a estrutura rígida, burocrática e centralizada das reformas. Assim,

a ampliação de direitos veio acompanhada de mudança nas formas de organização e gestão da educação, justificada pelos governos em diferentes âmbitos (municipal, estadual e federal) pela necessidade de modernização da administração pública como resposta aos reclamos por maior transparência, estruturas mais democráticas e flexíveis e maior eficiência (OLIVEIRA, 2015, p. 632).

Esse modelo de gestão pública se torna hegemônico e a partir de então observa-se sua preponderância inclusive em governos que se colocam no campo progressista popular (nos diferentes níveis). Tendo a avaliação como elemento fulcral, a implantação da NGP nas políticas educacionais é justificada pela busca da qualificação da educação.

A avaliação passou a constituir-se como um mecanismo central de regulação. Fornecendo indicadores que são utilizados nos estabelecimentos de metas de gestão e influenciando sobre o financiamento da unidade escolar e em alguns casos até mesmo na remuneração dos docentes. Além, é claro, de determinar em última instância os currículos (OLIVEIRA, 2015, p. 640).

$\mathrm{O}$ argumento central utilizado tem sido a necessidade de fornecer à sociedade um indicador de qualidade do ensino, a fim de permitir a mobilização dos agentes escolares no sentido de ajustar suas práticas com o objetivo de melhorar os resultados. Não se pode perder de vista, entretanto, que essa busca por eficiência através de bons resultados em avaliações de larga escala deixa de 
lado o processo histórico de construção da educação como um bem público, um direito social, que não pode ser regulado como uma mercadoria, deixando de considerar, ainda, as profundas desigualdades internas do sistema educacional brasileiro, além de despolitizar as relações entre o Estado e os cidadãos.

Tomando por base a ideia de que a NGP se configura em diferentes formatos, buscamos compreender suas repercussões na gestão educacional e escolar goiana. Para Verger (2015, apud TOLOFARI, 2005), nos lugares em que se aplicou a NGP, foi alterada de maneira significativa a forma como se concebe a gestão das instituições educativas, já que princípios como autonomia escolar, prestação de contas, gestão baseada em resultados ou eleição escolar penetraram profundamente na forma de regulação, provimento e financiamento dos serviços educacionais. Não se pode perder de vista, no entanto, que políticas educativas globais, como as que conformam a doutrina da NPG, são ativamente reinterpretadas e modificadas tanto pelos fazedores de política locais quanto pelos que materializam a política em última instância; professores, gestores e funcionários que atuam no chão da escola. Assim, é importante entender a hegemonia das soluções propostas pela NGP de um ponto de vista discursivo.

\section{A teoria do discurso como forma de apreensão da realidade}

Buscando compreender como a racionalidade da NGP tem sido incorporada pelos atores educacionais, optamos por utilizar a teoria do discurso de corte Lauclaniano.

Nesta pesquisa, o discurso foi tomado enquanto uma prática social, ou seja, como forma de construção social cuja condição ontológica é a política, o que implica em considerá-lo como uma forma de ação das pessoas sobre o mundo e sobre os outros, expressando as relações sociais que se colocam na sociedade. Constitui-se, portanto, em ações, seleções, escolhas, linguagens, enfim, todas as produções sociais das quais é expressão, podendo ser um caminho para o entendimento dos sentidos produzidos no "cotidiano".

O foco do trabalho foram as práticas discursivas (uma forma particular de prática social que se manifesta de forma linguística - falada ou escrita) que correspondem a momentos ativos no uso da linguagem, momentos de "ressignificação", de rupturas, de produção de sentidos e, portanto, de linguagem em ação.

Segundo Fairclough (2001, p. 66), em sua análise da obra de Foucault, 
o que é de maior significação aqui para a análise do discurso é a visão do discurso como constitutiva - contribuindo para a produção, transformação e a reprodução dos objetos da vida social. Isso implica que o discurso tem uma relação ativa com a realidade, que a linguagem significa a realidade no sentido de construção de significados para ela.

A análise de uma prática discursiva focaliza os processos de produção, consumo e mudança textual, o que exige referência aos ambientes econômicos, políticos e institucionais particulares nos quais o discurso é gerado. Porquanto,

[...] não há como dissociar o processo de apreensão do real de processos de significação, os quais, por sua vez, implicam tanto em redes argumentativas quanto nas práticas concretas e nas instituições através das quais tais representações podem tornar-se significativas, compartilhadas ou impostas (conforme o façam por via democrática ou autocrática). Enfim, significa admitir uma acepção do termo que indica sua dinamicidade, o jogo das diferenças num sistema que altera os limites de sua própria configuração: discurso (BURITY, 1994, p. 149, grifo do autor).

Nessa perspectiva, o discurso inclui tanto o linguístico quanto o extralinguístico, na medida em que todas as configurações sociais são significativas e, assim, os significados das palavras e práticas dependem do espaço discursivo em que se colocam, construídos por práticas articulatórias. Na perspectiva laclauliana, portanto, a política é a disputa pela significação.

Segundo Fairclough (2001, p. 91),

o discurso contribui para a constituição de todas as dimensões da estrutura social que, direta ou indiretamente, o moldam e restringem: suas próprias normas e convenções como também relações, identidades e instituições que the são subjacentes. O discurso é uma prática, não apenas de representação do mundo, mas de significação do mundo, constituindo e construindo o mundo em significação.

$\mathrm{O}$ autor identifica três funções da linguagem e dimensões de sentido que coexistem em todos os discursos. A primeira é a função identitária, que se relaciona aos modos pelos quais as identidades sociais se estabelecem no discurso. 
A segunda função, a relacional, diz respeito à maneira como as relações sociais entre os participantes de processos discursivos são representadas e negociadas. E, por fim, a função ideacional é referente aos modos pelos quais os textos significam o mundo e seus processos, entidades e relações.

Enquanto prática social, o discurso é tomado como prática política, que transforma, mantém e estabelece as relações de poder e as entidades coletivas em que tais relações se colocam, havendo, portanto, uma competição para fixar sentidos $^{4}$ a configurações significativas particulares. Dessa forma, a hegemonia se fixa de forma contingente.

Segundo Laclau e Mouffe (1989, p. 113),

discursos são estruturas descentradas onde os sentidos são constantemente negociados e construídos. Esta estrutura descentrada, ou 'totalidade' estruturada, ou ainda, discurso, é o resultado de práticas articulatórias estabelecendo relações entre elementos com diferenças não articuladas discursivamente.

Esta perspectiva de análise do discurso abre a possibilidade para reativação da origem política contingente do que é fixado e objetivamente apresentado, abrindo espaço para novos antagonismos e fixação de novos conteúdos e formas que não se colocavam até então, tornando possível, assim, a articulação de uma multiplicidade de discursos concorrentes e, consequentemente, da transformação dos agentes e práticas sociais. Assim, a prática de articulação, como deslocamento/fixação de um sistema de diferenças, penetra a densidade inteiramente material da multiplicidade de instituições, rituais e práticas através das quais uma estrutura discursiva é estruturada (LACLAU; MOUFFE, 1985). Dessa forma, a prática discursiva tanto pode contribuir para a reprodução da sociedade como para sua transformação.

\section{A NGP e a gestão da educação no estado de Goiás}

A fim de compreender as repercussões da NPG na rede estadual goiana, realizamos entrevistas com o superintendente de gestão pedagógica da Secretaria de Estado da Educação (SEC), com a presidente do Sindicato dos Trabalhadores

4 Sentidos que são fixados de forma contingente, ou seja, são provisórios. 
em Educação (SINTEGO) e com os gestores da escola de maior e de menor IDEB da rede estadual ${ }^{5}$, além da pesquisa dos programas da SEC, que foram analisados com base nos pressupostos da Teoria do Discurso, de corte Laclauliano. Em função dos limites deste texto, focaremos na análise das entrevistas, utilizando os dados da SEC apenas para contextualização.

A educação se insere no Programa Goiás Mais Competitivo e Inovador, que "é um programa de desenvolvimento da competitividade e melhoria da gestão pública no estado de Goiás que abrange todas as áreas de atuação governamental e tem por foco a melhoria de indicadores sociais que impactam positivamente na qualidade de vida do cidadão" (GOIÁS, 2018). O programa apresenta três (03) eixos: competitividade econômica; qualidade de vida; e gestão pública efi-

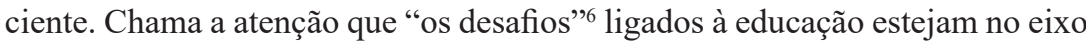
de competitividade econômica. São eles: elevar a qualidade do aprendizado da rede pública; promover o acesso à educação infantil; e promover a expansão e qualificação da oferta de educação profissional de nível técnico. Para o alcance desses desafios, há projetos como gestão escolar por resultados; aprender mais; rede do Instituto Tecnológico de Goiás (ITEGO - OS); ITEGO inovador; Goiás parceiro da educação infantil, entre outros.

Quando questionamos o Superintendente de Gestão Pedagógica sobre essa relação, foi colocado que "a gente acredita plenamente nisso". Justifica que a formação está atrelada ao desenvolvimento econômico do estado. "Um estado que investe em educação cria oportunidades". Ressalta, ainda, que foi contratado um consultor que explicou que

os territórios têm essas características, que você tem territórios, que você tem um desenvolvimento econômico muito grande, uma pujança econômica, mas ele não forma profissionais. O que vai acontecer? Como ele não forma, ele vai ser um estado sempre atraindo, trazendo gente para lá, porque ele tem mais dificuldade de fazer esse desenvolvimento, porque não tem profissionais.

A avaliação, política educativa que expressa o princípio da NGP da ênfase no controle de resultados, é fulcral em todos os discursos, seja da secretaria, de gestores e até mesmo do sindicato. Veja-se:

5 Nesta pesquisa as escolas militarizadas da rede estadual não foram consideradas devido às suas peculiares características.

6 Cada eixo contém desafios que são transformados em programas de ação, com objetivos, justificativa e metas a alcançar, ao qual são vinculados projetos específicos. 
"Os professores gostam disso, ficam felizes em saber que Goiás é campeão no resultado do IDEB" (Sindicato dos Professores).

"Os pais hoje escolhem a escola por boas referências. 2017 trabalhamos como loucos para melhorar os resultados" (Escola de Menor IDEB).

"Nós desenvolvemos uma avaliação formativa" (Secretaria de Educação).

Chama a atenção o discurso da Secretaria de Educação sobre a avaliação formativa. Segundo seu depoimento, a avaliação, realizada bimensalmente, tem o propósito de identificar dificuldades e trabalhar em cima delas. "A secretaria bimestralmente aplica uma prova, a gente analisa essa prova, a gente dá devolutiva para rede desse resultado, em 7 dias". Tal discurso é corroborado pela diretora da escola de menor IDEB, que diz utilizar a avaliação para reforçar as defasagens de aprendizagem dos alunos individualmente.

No entanto, o sindicato diz haver uma farsa nesses resultados, tendo em vista que há uma proibição de se reprovar alunos na rede estadual e de se registrar o abandono, que é tratado como transferência. Apesar dessa leitura, o sindicato não se pronuncia denunciando.

Existe um silêncio nosso. Por que um silêncio nosso? Porque nós sabemos a verdade. E então por que vocês não denunciam? Porque eu iria magoar meus profissionais, profissionais da educação. Eu ia comprar uma briga desnecessária, digamos assim. O que é que eu ganharia com isso? A quem interessa a minha denúncia? Os professores gostam disso, ficam felizes em saber que o estado de Goiás é campeão nesse resultado do IDEB (Sindicato dos Professores).

O discurso da dirigente sindical mostra quão introjetado ${ }^{7}$ está o processo avaliativo nas redes públicas. O sindicato verifica distorções, mas não as denuncia sob pena de perder apoio da categoria. Essa postura demonstra um apoio dos professores aos processos de avaliação em larga escala, sejam eles nacionais ou locais. Em Goiás isso é tão forte que cada escola tem uma placa em sua entrada na qual são colocados os resultados do IDEB, a cada edição, mostrando, assim, a evolução da escola no processo avaliativo. Essa publicação, a nosso ver, incentiva a competição e comparação entre as escolas. Chamou-nos a atenção a reação de surpresa da dirigente quando esclarecemos que "sua" escola tinha tido

7 Segundo Dardot e Laval (2016, p. 317), “a interiorização das normas de desempenho, a autovigilância constante para adequar-se aos indicadores e a competição com os outros são ingredientes dessa 'revolução de mentalidades' que os 'modernizadores' desejam realizar'. 
a menor nota no IDEB na última avaliação. Houve uma reação negativa e uma tentativa constante de justificação da nota, muitas vezes em tom comparativo "nós aqui fazemos assim, sabemos que outras escolas não fazem desse jeito, mas é o correto". A diretora, inclusive, não autorizou a gravação de sua entrevista.

Todos os discursos dos entrevistados, assim como os documentos da política educacional, apontam para o sentido de melhoria do IDEB e do Sistema de Avaliação Educacional do Estado de Goiás (SAEGO) e alcance de metas pré-definidas. Haveria várias passagens das entrevistas realizadas a serem destacadas que extrapolam os limites deste texto. Há uma clara hegemonia do discurso da importância da avaliação em larga escala e do próprio orgulho com os resultados alcançados no estado. Mesmo com posicionamento crítico, como é o caso do sindicato, o discurso da avaliação e dos bons resultados alcançados na rede se coloca como hegemônico. Dessa forma, podemos afirmar que há um claro alinhamento aos pressupostos da NGP no discurso sobre avaliação na rede estadual goiana.

No entanto, o alcance desses resultados passa por práticas afinadas a um projeto progressista de educação, especialmente no tocante à gestão democrática, com ênfase na eleição de diretores e atuação dos Conselhos Escolares. É consenso entre os entrevistados que há uma gestão democrática implantada na rede e que essa gestão contribui de forma decisiva para os resultados obtidos.

É um dado positivo dentro das escolas né. Porque ai todo mundo está escolhendo, têm as discussões. Mesmo com problemas, com a eleição diminuiu os problemas demais [...]Uma das coisas, uma das premissas muito importante nesse programa que a gente observou aqui em Goiás, é a questão da corresponsabilidade. Então, essa é uma, para te dizer a verdade, é umas das principais premissas (Escola de maior IDEB).

Então, assim, é um Conselho muito ativo, participa muito das decisões da escola. Das decisões e de tudo, principalmente da parte financeira, administrativo-financeira" (Escola de menor IDEB).

Os diretores eleitos democraticamente são "profissionalizados" em uma formação ofertada pelo Instituto Unibanco, cujo objetivo é voltar os gestores para o pedagógico, a fim de alcançar os resultados esperados. "Porque se nós queríamos melhorar o nosso desempenho, a gente precisa melhorar os nossos gestores, qualificar esses gestores" (Secretaria de Educação). Há, portanto, um entendimento do pedagógico como bons resultados nas avaliações. 
A profissionalização dos gestores assim como a ênfase no controle dos resultados de avaliações de larga escala são princípios da NPG na educação, conforme aponta Verger (2015). Na rede estadual goiana, esses princípios estão sedimentados no discurso dos entrevistados, aliados, no entanto, a uma perspectiva de gestão democrática, com ampla participação da comunidade escolar e compartilhamento de decisões.

Uma política apontada por Verger (2015) para o alcance do princípio de normas e medidas de desempenho mais explícitas é a padronização curricular. Goiás dispõe de um currículo de referência para a toda a rede desde 2011.

Esse currículo, ele permitiu, por exemplo, nós desenvolvermos um sistema de avaliação, não só o sistema de avaliação externo, que é como $C A E D^{8}$, nos moldes do IDEB, só que ele é anual. Mas construir, o que na minha avaliação teve um impacto muito forte, é uma avaliação diagnóstica formativa. A secretaria bimestralmente aplica uma prova, a gente analisa essa prova, a gente dá devolutiva para rede desse resultado, em 7 dias. Isso só foi possivel por causa desse currículo. A própria construção de material estruturado completar foi algo, inclusive, que nós vimos lá no Pernambuco e trouxe para cá em 2012, a gente começou a trabalhar com material estruturado, a gente trabalha com isso até hoje. Hoje, claro, a gente vem ajustando. A gente tem uma estrutura de acompanhamento das escolas e esse acompanhamento ele é por meio de uma metodologia própria, que é a tutoria (Secretaria de Educação).

Como podemos depreender do discurso da secretaria, o currículo único tem estreita relação com a avaliação e foi um importante elemento para os resultados exitosos que a rede vem alcançando. A gestora da escola de menor IDEB destaca, inclusive, que em toda a rede o currículo é o mesmo, o que facilitou o desenvolvimento pedagógico, especialmente em casos de transferência, pois todas as escolas trabalham o mesmo conteúdo. No entanto, os alunos que vem de outra rede sentem dificuldade em acompanhar o conteúdo.

Por fim, é clara a adoção dos parâmetros do setor privado na gestão das escolas, assim como as parcerias que são desenvolvidas com vários institutos desse setor. Quase todos os programas adotados na rede são desenvolvidos em parceria com o setor privado: Itaú Social, Instituto Unibanco, Todos pela Educação, Instituto de Corresponsabilidade pela Educação (ICE), Instituto Ayrton Sena, CAED.

8 Centro de Políticas Públicas e Avaliação da Educação da Universidade Federal de Juiz de Fora. 
A gestão escolar por resultados é a parceria que nós temos com o Instituto Unibanco, inclusive esse ponto de gestão. A gente tem uma percepção que as escolas de sucesso, via de regra, elas têm uma gestão de sucesso. O gestor de uma empresa, essa pessoa... você chega numa escola, você percebe que é bem gerida, ela dá bons resultados. Nós, aqui em Goiás, a gente tem um modelo de gestão democrática, então o professor se candidata a partir de um curso, e tal. Mas ele se candidata e ele é eleito para gerir aquela escola por um periodo e nem sempre aquele profissional tem uma formação de gestão. Então, a ideia do projeto foi formar esse gestor (Secretaria de Educação).

Olhe, aqui é o estilo de uma escola particular! O aluno sempre vai fazer prova, tem prova 2, 3 vezes durante a semana. Ele tem que ter um momento de estudo, senão ele não consegue acompanhar! (Escola de maior IDEB).

Como aponta os extratos de fala, o modelo de sucesso é o da escola particular, tanto no que se refere à gestão das escolas quanto nas atividades cotidianas, o que sugere o alinhamento da rede de educação goiana à NGP. Como exposto no início deste texto, a base da NGP é a adoção de práticas de gestão empresarial no setor público, o que parece estar se dando na educação estadual goiana.

\section{Finalizando...}

O estudo da política educacional goiana demonstrou seu alinhamento aos preceitos da NGP. Dessa forma, podemos afirmar que a Nova Gestão Pública se constitui como ponto nodal ${ }^{9}$ na educação goiana, na perspectiva da Teoria do Discurso.

Centralidade das avaliações, gestão por metas e resultados, profissionalização da gestão, competitividade, padronização curricular e parceria com instituições do setor privado se constituem como elementos definidores da política educacional goiana. Assim, os princípios da NPG são hegemônicos na rede estadual. O tripé objetivos-avaliação-sanção - ou recompensa - (DARDOT; LAVAL, 2016) está consolidado na rede estadual goiana. Assim, estaria sedimentado um dos principais objetivos da NGP de transformar as administrações públicas tradicionais em organizações voltadas para o desempenho.

9 Fixação contingente de sentidos que se universalizam. 
No entanto, há um alinhamento da gestão gerencial, com base na NGP, à gestão democrática, característica de outro projeto educativo. Há um consenso de que a rede implantou e consolidou a gestão democrática e de sua importância para o alcance dos resultados obtidos nas avaliações, que vêm colocando Goiás em destaque no cenário educacional brasileiro. Dessa forma, podemos afirmar que tal qual os princípios da NGP, a gestão democrática pode ser considerada um ponto nodal na política educacional goiana.

Essa contradição reforça a compreensão de que a instituição da NGP na educação não pode ser considerada como um modelo monolítico, de formato único. Abre, ainda, a possibilidade de implantação de práticas transformadoras não alinhadas a seus preceitos básicos. Há, nas escolas e na rede goiana, uma clara sedimentação da NGP, especialmente no que se refere ao alcance de metas e resultados em avaliações. Mas também há uma clara sedimentação da importância da gestão democrática.

Assim, o discurso hegemônico apresenta elementos de perspectivas teóricas distintas, que não se colocam como antagônicas no chão da escola, como expresso na literatura, mas sim de forma complementar, o que aponta, portanto, para a necessidade de aprofundamentos de estudos desta natureza que possam, inclusive, a partir da realidade empírica, fazer uma revisão nos aportes teóricos da temática, sem abandonar, entretanto, uma visão crítica da NGP.

\section{REFERÊNCIAS}

BRESSER PEREIRA, L. C. Crise econômica e reforma do Estado no Brasil. São Paulo: Editora 34, 1996.

BURITY, J. Transbordamento do social: qual o jogo da democracia? In: SANTOS, R.; CUNHA, R.; COSTA, L. F. (Org.). Contemporaneidade e política. Rio de Janeiro: Sociedade do Livro; Instituto Astrogildo Pereira, 1994. p. 137-158.

CENTRO LATINO AMERICANO DE ADMINISTRAÇÃO PARA O DESENVOLVIMENTO. Uma nova gestão pública para a América Latina. 1998. Disponível em: www. bresserwesite.org.br. Acesso em: 15 jul. 2008.

DARDOT, P.; LAVAL. C. A nova razão do mundo: ensaio sobre a sociedade neoliberal. São Paulo: Boitempo, 2016.

DASSO JÚNIOR, A. E. Nova gestão pública: a teoria da administração pública do estado ultraliberal. 2014. Disponível em: htpp://www.publicadireito.com.br/ artigos/?cod=d05c25e6e6c5d489. Acesso em: 08 mar. 2018. 
FAIRCLOUGH, N. Discurso e mudança social. Brasília: Editora da Universidade de Brasília, 2001.

GARCIA, T.; ADRIÃO, T.; BORGHI, R. A nova gestão pública e o contexto educacional brasileiro. In: MARTINS, M. (Org). Instituições educacionais: políticas, gestão e práticas profissionais. Santos: Editora Universitária Leolpodianum, 2009, p. 9-23.

GOIÁS. Programa Goiás Mais Competitivo. O GMCI - Programa Goiás Mais Competitivo. 2018. Disponível em: http://www.goiasmaiscompetitivo.go.gov.br/ pagina/14609/o-gmci. Acesso em: 08 mar. 2018.

JUNQUILHO, G. D. Reforma gerencial o "gerente caboclo" frente os desafios da reforma do Estado no Brasil. Anais do VII Congreso Internacional del CLAD sobre la Reforma del Estado y de la Administración Pública. Lisboa, Portugal, 2002, p.1-23.

LACLAU, E.; MOUFFE, C. Hegemony and socialist strategy. London: Verso, 1985.

. Hegemony \& socialist strategy: towards a radical democratic politics. London and New York: Verso, 1989.

OLIVEIRA, D. A. Nova gestão pública e governos democráticos populares: contradições entre a busca da eficiência e a ampliação do direito à educação. Educação e Sociedade. Campinas, v. 36, n. 132, p. 625-646, jul.-set., 2015.

. A nova gestão pública no contexto escolar e o dilema dos (as) diretores (as). Revista Brasileira de Política e Administração da Educação. v. 33, n. 3, p. 707-726, set.-dez., 2017.

VERGER, A. Nueva gestión pública e educacion: elementos teóricos y conceptuales para el estúdio de um modelo de reforma educativa global. Educação e Sociedade. Campinas, v. 36, n. 132, p. 625-646, jul.-set., 2015.

Texto recebido em 02/08/2019.

Texto aprovado em 10/11/2019. 